\title{
CLARICE LISPECTOR E A POÉTICA DO VIVENDO'
}

\section{CLARICE LISPECTOR AND THE POETIC OF LIVING}

Fernando de Mendonça²

RESUMO: A partir de uma declaração de Clarice Lispector, nos anos 1960, sobre a literatura ser uma experiência em modo gerúndio ('vida vivendo'), propomos uma análise de sua escritura que concentre os efeitos estéticos do texto literário como prolongamento do corpo autoral. Para isso, focamos o romance Um Sopro de Vida (1978), retomando leituras de Olga de Sá (1993; 2004) e a reconstituição biográfica de Benjamin Moser (2009), também ampliando as possibilidades de interpretação por um viés teopoético, com base no conceito de Orgé, do alemão Rudolph Otto (2007), haja vista a relação do texto clariceano com as manifestações do divino.

Palavras-chave: Poética literária. Teopoética. Clarice Lispector.

ABSTRACT: From a statement by Clarice Lispector, in the 1960s, about literature being a gerund mode experience ('living life'), we propose an analysis of her writing that concentrates the aesthetic effects of the literary text as a prolongation of the authorial body. We focus on the novel Um Sopro de Vida (1978), retaking readings by Olga de Sá $(1993 ; 2004)$ and the biographical reconstitution of Benjamin Moser (2009), also expanding the possibilities of interpretation by a theopoetics perspective, based on the concept of Orgé, from the german Rudolph Otto (2007), considering the relation of the claricean text with the manifestations of the divine.

Keywords: Literary poetics. Teopoetics. Clarice Lispector.

\section{Introduçăo}

\section{(em tempo gerúndio)}

É praticamente um consenso a constatação de que palavra e vida, em Clarice Lispector (1920-1977), são elementos inseparáveis, que se auto alimentam ininterruptamente e chegam a confundir os episódios do cotidiano da autora com os de suas ficções. Não é possível pensar a existência de Clarice sem o que ela naturalmente desdobrou nos livros,

\footnotetext{
${ }^{1}$ Artigo recebido em 14 de agosto de 2019 e aceito para publicação em 21 de novembro de 2019.

2 Doutor em Letras pela UFPE; Professor de Teoria da Literatura na UFS (DELI/PPGL); Membro do Núcleo de Estudos em Literatura e Intersemiose (NELI - UFPE) e do Grupo de Estudos em Filosofia e Literatura (GEFELIT - UFS); E-mail: nandodijesus@gmail.com
} 
assim como chega a ser leviano considerar sua matéria textual sem levar em conta particularidades de sua biografia. Das crônicas aos contos, da literatura infantil aos romances mais experimentais, tudo o que ela provou com as letras foi um claro prosseguimento do seu dia-a-dia, uma espécie de segunda pele ou segunda camada de vivência impossível de descascar. Em entrevista a Leo Gilson Ribeiro, no início dos anos 1960, ela revelou: “Eu acho que a literatura não é literatura, é vida vivendo." (LISPECTOR, apud MOSER, 2009, p. 330) Daí optarmos por assim batizar a sua poética íntima, a sua prática do verbo, no mesmo sentido de permanente gerúndio que verificamos ocorrer de maneira recorrente em toda a sua obra ${ }^{3}$.

Se os leitores parecem concordar com este espelhamento poético na vida da escritora, cabe trazermos pelo menos uma destas visões, onde nos valemos da atenta observação de Olga de Sá:

Há, portanto, como subtexto, na obra clariceana, uma ars poética ou mais simplesmente uma 'poética', que laboriosamente dela podemos desentranhar. Virão juntos, grudados ao osso dessa poética, pedaços de Clarice mesma, pois ela jamais se distanciou de seu texto. É possível, pois, que esse trabalho de desencavar e ordenar, além de nos doar o que Clarice pensava da ficção, nos forneça, 'de quebra', o princípio de algumas de suas escolhas, entre todos os possíveis itinerários como escritora - e teremos assim, também a sua 'poética', num segundo sentido. (SÁ, 2004, p. 203)

Diante disso, nosso interesse está bem delimitado: ordenar estes fragmentos de vida, para assim vislumbrar o sentido da ficção clariceana, mas também do que Clarice entendia e sentia por esta ficção. $O$ exercício metalinguístico, constante neste itinerário criativo, deixa de ser mera especulação de linguagem para alcançar o próprio fôlego da vida autoral, num sofisticado e abrangente uso da escrita como prolongamento do corpo $^{4}$, especialmente em obras paradigmáticas de sua maturidade, como

\footnotetext{
3 Já se observou (MELLO, 1987) que os tempos verbais mais utilizados por Clarice são os 'durativos': o imperfeito do indicativo e o gerúndio. Isto acentua a ideia de fluir contínuo no tempo e reforça o caráter de incerteza típico da literatura ficcional que a autora realiza.

${ }^{4}$ Aqui prosseguimos, em parte, o que foi refletido em uma de nossas pesquisas anteriores sobre a autora, com ênfase aos feitos de Água Viva: "A iminência do autobiográfico, com toda a força que aqui se permite explicitar, ultrapassa a ideia de uma escrita (grafos) da vida (bio), fixando-se no âmago da própria vida, como se na obra o corpo de Clarice não pudesse jamais deixar de pulsar." (MENDONÇA, 2011, p. 94)
} 
Água Viva (1973) e Um Sopro de Vida (1978), motivo pelo qual escolhemos esta última para aqui aprofundar a noção de uma energia criativa vital, em relação potencial e direta com a Orgé divina (conceito que retomaremos mais adiante).

O comentário de Olga prossegue: "A poética de Clarice pode ser visualizada como a reversão paródica da ilusão ficcional, arrancando-lhe a máscara: o desnudamento da ficção, uma poética do escrever = viver, do sopro de vida, do escrever morrendo para se salvar." (SÁ, 2004, p. 218) É na força destes deslocamentos narrativos e ficcionais que nos concentramos para também entender a forma como a escrita passa a representar um ato de redenção, um canal para Deus e para as forças que sustentam a vida. Nada mais natural para uma mulher que carrega em si toda uma herança de seus ancestrais judaicos e que, pela palavra, expurga as limitações profanas do Ser. Nesta tradição, não é figura de linguagem a consciência de que escrever é (sobre)viver, pois foi pelo verbo que a memória de seu povo se manteve no correr da história, assim como adquiriu uma estreita relação com a soberania de Deus. Como ela bem coloca, em A Hora da Estrela: "Desde Moisés se sabe que a palavra é divina." (LISPECTOR, 1998, p. 79) Sendo assim, não há como fugir do espírito, dentro de sua literatura.

Sob todos os aspectos, Um Sopro de Vida é um dos livros de Clarice que mais escapa ao romanesco, aos gêneros literários de forma geral. Seu predecessor, Água Viva, denominado pela autora como 'ficção' (não como romance ou novela, como faria em outras obras), pode bem representar o que há de mais extremo no tratamento linguístico da escritora. Um livro sem enredo, sem começo nem fim, e que, por esta própria estrutura, já guarda uma enorme proximidade com o ideal divino. A presença narradora, em incontáveis momentos da duração escritural, se refere ao Deus, assim como arrisca a adoção de perspectivas que tentem compreender o olhar de Deus. Nesse sentido, o que de fato nos interessa, são os momentos em que o texto evidencia uma ligação singular entre a necessidade da escrita e da sobrevivência, uma confrontação com o impossível e o incomensurável, como vemos muito claramente nos seguintes casos de Água Viva: "Mas escrever para mim é frustrador: ao escrever lido com o impossível. Com o enigma da natureza. E do Deus. Quem não sabe o que é Deus, nunca poderá saber. Do Deus é no passado que se soube. É algo que já se sabe." (LISPECTOR, 1973, p. 87) “Mas se não 
compreendo o que escrevo a culpa não é minha. Tenho que falar porque falar salva. Mas não tenho nenhuma palavra a dizer. $O$ que é que na loucura da franqueza uma pessoa diria a si mesma? Mas seria a salvação." (idem, p. 102)

Diante destas transcrições, podemos logo observar a maneira como a dimensão da palavra se aprofunda em Um Sopro de Vida, livro que indica continuidade ao projeto de 1973, duplicando a necessidade criativa no diálogo entre criador e criatura. Temos aqui o conflito de duas vozes, a de um Autor e a de uma Personagem, em pleno processo de criação literária. A maneira como Clarice mergulha em ambos, referindo-se explicitamente a expressões suas e obras de seu passado, complementa a grafia de sua vida pessoal na fiç̧ão. Consideremos, inicialmente, alguns ecos que acentuam o paralelo entre os dois livros, na compreensão que tomam da palavra como um acesso ao divino: "Pois escrever é coisa sagrada onde os infiéis não têm entrada." (LISPECTOR, 1999, p. 21) "Às vezes escrever uma só linha basta para salvar o próprio coração." (idem, p. 103) "Deus é uma palavra? Se for estou cheio dele: milhares de palavras metidas dentro de um jarro fechado e que às vezes eu abro - e me deslumbro. Deus-palavra é deslumbrador." (idem, p. 127)

Palavras que denotam o exato interesse por uma escrita envolvida pela presença divina, que aproxime o Autor de Deus justamente através do gesto criador. Pois aí uma obra que, desde a primeira epígrafe, colhida no grande Livro da Criação, o Gênesis bíblico (Do pó da terra formou Deus-Jeovah o homem e soprou-Ihe nas narinas o fôlego da vida. E o homem tornou-se um ser vivente.), identifica o objetivo de localizar, em algum nível da linguagem, esta mesma condição criadora, de dar fôlego, de tornar à vida, de instaurar mundos, desde o seu próprio título, Um Sopro de Vida.

O Autor clariceano, consciente de seu espelhamento ao Deus, afirma: "O que a nossa imaginação cria se parece com o processo que Deus tem de criar." (idem, p. 135) E, talvez por isso, ele reconhece a dificuldade de elaborar sua Personagem, Ângela Pralini, como se exprimisse a voz mesma de Clarice: "Descobri por que soprei na carne de Ângela, foi para ter a quem odiar. Eu a odeio. Ela representa a minha fé terrível que renasce todos os dias de madrugada. E é frustrador ter fé." (idem, p. 132)

Ora, não temos dúvidas de que o ato narrativo surge em reflexo à fé de sua criadora, assim como o Autor deste seu último livro (sua 
publicação é póstuma, para Clarice) vem comunicar todo o pensamento autorreflexivo que percorreu a carreira em questão. Sobre esta voz narradora, temos: "O Autor é a síntese dos autores implícitos de todos os livros de Clarice Lispector." (SÁ, 2004, p. 209) Sendo assim, ele pode representar não somente a crise de uma personagem, mas aquela energia que nela brota a partir da Orgé.

\section{Entre a letra e Deus: a energia criativa}

Foi quando o ser humano se descobriu só que a arte passou a conhecer a necessidade do abandono. A saudação se desfez. A aliança entre os referentes quebrou para dar lugar a uma nostalgia que encontraria na própria arte um reflexo do fragmentado mundo em que o ser, agora vazio e solitário, passa a existir. Uma das principais características da Modernidade é justamente a condição errante e autônoma do indivíduo; "no Novo Mundo, ser homem significa ser solitário." (LUKÁCS, 2009, p. 34) Por isso é natural que a arte acompanhe o processo de desprendimento do mundo, passando a níveis de representação distintos dos procedimentos clássicos de imitação, onde não é mais possível priorizar fidedignidades exteriores, mas sim deixar brotar de sua superfície (da obra), uma motivação própria, original; "ela não é mais uma cópia, pois todos os modelos desapareceram; é uma totalidade criada, pois a unidade natural das esferas metafísicas foi rompida para sempre." (idem) Ao abarcar o estado humano de abandono abandono do mundo, do Outro, do Deus, da confiança e da identificação primeira que ele nutria com o além de si -, a arte também abandona a tudo que desamparou o humano, passando a atender por suas formas o insuperável anseio do espírito.

É nesta perspectiva que o projeto criativo de Clarice Lispector se fundamenta, em plena sintonia com o espírito do séc. XX. Não há como deixar de pensar numa postura beckettiana, por parte da escritora, diante do tempo histórico, assim como da literatura que cabe expressá-lo; a emblemática conclusão de O Inominável (1949), de "não poder continuar, mas ter que continuar", na angustiada esperança que resta ao verbo, ecoa muito da continuidade que vemos aflorar nos textos clariceanos. $O$ que se identifica, no rastro de Beckett, é uma necessidade primeira em questionar a própria validade da palavra para encontrar nela força de expressão. Com esse questionamento, é possível se aproximar do esforço criativo que nossa 
autora dedica, especialmente, à luz do que enxergamos no eixo temático da estrutura teológica do alemão Rudolph Otto (2007), à qual recorremos para auxílio de nossas interpretações.

Em primeiro lugar, importa alguma síntese que defina a categoria da Orgé (ira) divina, levantada por Otto como um dos níveis da experiência numinosa, na estrutura do Mysterium Tremendum. Segundo o teólogo, trata-se de um elemento expresso "simbolicamente na vivacidade, paixão, natureza emotiva, vontade, força, comoção, excitação, atividade, gana" (OTTO, 2007, p. 55), sendo que todas estas expressões são primeiramente originadas em Deus ${ }^{5}$ e por Ele sentidas, para então se verem refletidas na face humana desta relação. Num sentido pragmático, é como se fosse esta a resposta, o ímpeto e o impulso de reagir ao que primeiro se experimenta, um tanto quanto passivamente, em uma relação com o divino. Fica bem claro que, nesta fase da mística, no encontro desta energia, cabe ao elemento humano ir além de sua estagnação e impotência iniciais, já que a Orgé "[...] aciona a psique da pessoa, nela desperta o zelo (eifer); ela é tomada de assombrosa tensão e dinamismo: na prática ascética, no empenho contra o mundo e a carne, na excitação a eclodir em atuação heroica." (idem)

$\mathrm{Na}$ escrita como resistência, encontramos este pleno empenho em Clarice, refletido na maneira como se articula a linguagem, na 'zelosa literatura' que termina por realizar. $\mathrm{O}$ ato de escrever, não somente para a autora, mas para os ecos metalinguísticos de suas personagens e de tantas obras em paralelo no correr de sua carreira, subsiste como um derradeiro estágio de sua libertação. Escreve para negar uma condição, para ocupar o descobrimento de uma ausência, para trabalhar sob a superfície da memória que carrega não somente do tempo, mas da própria pele. Finalmente, escreve para sobreviver ao Deus. E, se arriscamos significar a escrita como um fruto simbólico da Orgé, o fazemos ancorados nas próprias considerações de Otto a respeito dos 'meios de expressão do numinoso na arte', título de um sub-tópico de sua obra.

"Nas artes, o mais eficiente meio de representar o numinoso é quase sempre o excelso." (idem, p. 105) Diante da afirmativa, podemos

${ }^{5}$ Trata-se de uma leitura antropomórfica de Deus: "do grego anthropos = homem + morphe = forma. Atribuição de qualidades ou formas humanas a Deus." (SCHÜLLER, 2002, verbete antropomorfismo) 
considerar o excelso como um claro sinônimo do sublime ${ }^{6}$, igualmente lembrado dentro de uma aproximação kantiana: “Entre o numinoso e o excelso existe uma afinidade e relação oculta que não é mera semelhança acidental. Até a 'Crítica do Juízo' de Kant é remoto testemunho disso." (idem, p. 102) Eis a noção divina que toma o lugar do Terrível, enquanto meio de expressão e comunicação com o ser humano; também o que desperta a clara necessidade de se completar e ampliar este diálogo.

Nossa intenção de agora observar o trabalho de Clarice como consequência imediata da manifestação excelsa, decorre do 'acionamento da psique' apontado por Otto, dentro do que se aciona na percepção leitora. $\mathrm{Na}$ expressão do numinoso, seja nas artes ou em qualquer meio de contato entre psiques distintas, deve-se lembrar de que aí não lidamos com um ente que possa ser exatamente comunicado. Deus não é 'ensinável', como diz Otto, Ele é 'despertável', a partir do espírito. Sendo assim, a perspectiva da literatura ficcional surge como uma via de escape, ultrapassando o domínio da representação para estimular no leitor a consciência do que um encontro com o divino pode acarretar. Através da letra, não se alcança a natureza do objeto focado pela escrita, mas a ação dele sobre o indivíduo. É um processo quase intuitivo, calcado na sensibilidade das formas; mesma intuição que nos condiciona ao emanar do Sublime, também lembrada pelos pensadores que sobre este conceito atentam.

A influência do ponto de vista teológico de Schleiermacher pode esclarecer alguns desdobramentos de Otto: "Todo intuir parte de um influxo do intuído sobre o que intui, de uma ação originária e independente do primeiro, que depois é assumida, recompilada e compreendida pelo segundo de uma forma acorde com sua natureza." (SCHLEIERMACHER, 2000, p. 36) A ação originária que buscamos em Um Sopro de Vida pode bem ser encontrada em outros âmbitos da obra escritural em questão. $O$ que pretendemos, então, é verificar a maneira como Clarice 'recompila' esta intuição na superfície de sua obra, no domínio supremo de sua natureza. Pois, não negamos: eis uma natureza que só se revela plena por intermédio

${ }^{6}$ Walter O. Schlupp, tradutor de Otto para o português, esclarece em nota o uso do termo Erhaben, que lemos como Excelso: "A versão inglesa usa 'sublime', cujo homônimo português Houaiss apresenta como sinônimo de excelso, inclusive situando-o preponderantemente na estética, como Otto. [...] A raiz do termo 'excelso', adotado para traduzir erhaben, apresenta essa conotação, como particípio do verbo latino excellere: 'elevar-se acima de" (OTTO, 2007, p. 25) 
de sua poética. Plena, porque em perpétuo presente de 'vida vivendo'. Se há uma compreensão discernível do sagrado na vida desta escritora - e de fato, o biográfico é algo que pode em muito nos ajudar -, esta só se efetiva por inteiro no tratamento que pode receber de seus textos, naquela insistência beckettiana de continuar em frente, por mais que as circunstâncias sejam contrárias.

Acreditamos já estar clara a dimensão ontológica da palavra clariceana, de toda a sua voz, assim como de seu silêncio, nas rupturas até mesmo visuais que ela costuma dar ao tratamento final de seus livros. Mas sobre esta posição (do silêncio), ainda cabe mencionar uma das decisões textuais do Autor, em Um Sopro de Vida: "Preciso ficar só de mim, a ponto de não contar nem com Deus. Para isso, deixo em branco uma página ou o resto do livro - voltarei quando puder." (LISPECTOR, 1999, p. 134) Por meio desta declaração, entendemos que a página em branco é a única maneira de silenciar o contato com Deus, de afastar-se Dele conscientemente, o que completa o sentido antes encontrado da palavra escrita, de uma forma que não apenas vem representar algum nível desta relação vertical, ou mediá-lo para a percepção leitora, mas, muito além, vem instaurar a plenitude da experiência com Deus, vem formá-Lo, como um dia Ele nos formou, não por acaso, também pela Palavra.

Deriva da fé e tradição judaicas esta capacidade mística de nomear as coisas, de transcender a representação do que existe no mundo para fazer com que o mundo, efetivamente, exista. Na compilação biográfica organizada por Benjamin Moser (2009), a busca pela Palavra em Clarice torna-se o núcleo existencial da trajetória vivida, uma busca que é de satisfação na linguagem, mas também de satisfação pessoal e de satisfação em Deus. A respeito deste ambicioso projeto, Yudith Rosenbaum comenta, em apresentação identificada na contracapa da publicação: “O autor vê na obra a incansável busca mística do judaísmo por uma origem enigmática, pela letra oculta de um Deus que a teria abandonado, busca a que ela jamais renunciou." (apud MOSER, 2009) A impressão que a literatura de Clarice nos deixa, enfim, é de que, se esta letra divina for encontrada, somente assim a subjetividade do espírito descansará em alguma harmonia. Para isto, somos constantemente lançados diante de fenômenos que só se perpetuam através da escritura, sendo símbolos, mas também entidades concretas e passíveis de percepção. 
A possibilidade de unir uma coisa e seu símbolo, de reconectar a linguagem à realidade e vice-versa, não é um empreendimento intelectual ou artístico. Em vez disso, está intimamente vinculada aos reinos sagrados da sexualidade e da criação. Uma palavra que não descreve uma coisa preexistente, mas de fato é essa coisa, ou uma palavra que cria a coisa que descreve: a busca dessa palavra mística, da 'palavra que tem luz própria', é a busca de uma vida inteira. Essa busca foi uma preocupação urgente de místicos judeus ao longo dos séculos. Assim como Deus, na escrita de Clarice, é completamente desprovido de qualquer sentido moral, também a linguagem não significa nada além daquilo que expressa: 'o símbolo da coisa na própria coisa'. (MOSER, 2009, p. 194)

O biógrafo articula tal raciocínio, enquanto discorre sobre os episódios que acompanharam o lançamento de Perto do Coração Selvagem (1944), romance de estreia da escritora e livro já repleto de caminhos e intervalos que buscam o divino. Assim como em Um Sopro de Vida, naquele livro a autora também dedicava uma maior concentração desta procura às últimas páginas de seu fluxo textual. É curiosa a maneira como em ambos, o direcionamento da linguagem, por mais que se trate de enredos que furtem a noção de clímax narrativo, caminhe num adensar das formas, restando às últimas partes dos livros, tanto o maior grau de experimentação linguística, como a mais concreta apresentação de uma proximidade e contato extremos com Deus.

\section{Consideraçōes finais}

Completamos esta condição de empenho escritural, confirmando o valor existente na relação dos textos de Clarice Lispector, pela maneira como esta manipula sua temporalidade narrativa. Suas personagens são desdobradas sob uma necessidade pela escrita que lhes é primeira, configurando e refigurando, para ficarmos em termos tão apropriados ao que se estabelece entre o tempo e a narrativa (RICOEUR, 1997), a própria experiência de seu sentimento pelo numinoso. Ainda que utilizem recursos distintos de temporalidade, como o processo do gerúndio e a presentificação do passado, elas não deixam de irradiar uma concentração do fenômeno vivido, na forma como fundamentam a narratividade de uma experiência; reconstituem o conjunto de operações externas, agindo 
incisivamente sobre os próprios textos e, sobre eles, estabelecem uma necessária 'mudança no modo de agir'. Pois é nesta postura enérgica de impulso e reação que a Orgé se efetua plenamente.

Há um empenho pela transformação que se manifesta como nuclear a Um Sopro de Vida. Mudança da consciência e da percepção, mudança de formas e recursos de linguagem, enfim, mudança que se desdobra do verbo divino ao verbo humano, no entrecruzamento de vozes que aí se origina. $\mathrm{O}$ resultado deste processo, aproveitando a lembrança de Ricoeur, culmina no exercício de uma 'hermenêutica de si', onde toda função referencial de mundo é transformada, reestruturada. Esta é a maneira como responde Clarice aos deslocamentos causados pela experiência numinosa, ao que se vislumbrou do Sublime, inclusive, a partir de suas letras. E daí um motivo que justifica a singularidade de sua obra, no que the demarca a diferença e mudança dentro de um cenário literário maior, seja nacional ou mundialmente. Não há como confundi-la, pois precisou encontrar uma voz particular, através de personagens (as inúmeras criadas), que dessem conta do lugar a ser ocupado por sua consciência.

Pela escrita se resiste ao mundo, ao que se perde no tempo, por ela se cria, se reencontra e se resiste ao Deus. Um Sopro de Vida dimensiona uma nova condição para o verbo, na forma como enfrenta as desestabilizações do intelecto e nos convida a partilhar sua reformulação na ordem das coisas. $E$, ao transcender o estado enérgico do contato com o divino, através do uso que faz da escritura ficcional, se reabilita ao enfrentamento do nível mais elevado deste catártico processo, aquele em que se pode ir mais longe na ascensão do espírito e da letra.

\section{Referências}

BECKETT, S. O Inominável. São Paulo: Globo, 2009.

LISPECTOR, C. Água viva. Rio de Janeiro: Artenova, 1973.

. A Hora da Estrela. Rio de Janeiro: Rocco

Um Sopro de Vida. Rio de Janeiro: Rocco, 1999.

LUKÁCS, G. A teoria do romance. 2. ed. São Paulo: Duas Cidades, 2009.

MELLO, M. A. B. O Tempo nos romances de Clarice Lispector: a eternidade versus a identidade. Travessia, n. 14, jun. 1987, p. 125-135. 
MENDONÇA, F. de. A Modernidade em diálogo: o fluir das artes em Água Viva. Recife: Ed. UFPE, 2011.

MOSER, B. Clarice, uma biografia. São Paulo: Cosac Naify, 2009.

OTTO, R. O sagrado: os aspectos irracionais na noção do divino e sua relação com o racional. Petrópolis: Vozes, 2007.

RICOEUR, P. Tempo e narrativa - Tomo 3, Campinas: Papirus, 1997.

SÁ, O. de. A escritura de Clarice Lispector. 2. ed. Petrópolis: Vozes, 1993.

Clarice Lispector: a travessia do oposto. 3. ed. São Paulo: Annablume, 2004

SCHLEIERMACHER, F. Sobre a religião: discursos a seus menosprezadores eruditos. São Paulo: Novo Século, 2000.

SCHÜLLER, A. Dicionário enciclopédico de teologia. Canoas: Ed. ULBRA, 2002 